\title{
Gambaran Activity Daily Living Pada Pasien Pasca Stroke Non Hemoragic Setelah Pemberian Propioceptive Neuromuscular Facilitation Literature Review
}

\author{
Rizqika Indah Yuli Yanti ${ }^{1 *}$, Nurul Aktifah ${ }^{2}$ \\ ${ }_{1,2}$ Prodi Sarjana Fisioterapi, Universitas Muhamamdiyah Pekajangan Pekalongan, Indonesia \\ *email:rizkikaindah17@gmail.com
}

\begin{abstract}
Stroke occurs when a blood vessel that carries oxygen and nutrients to the brain bursts or is blocked by a clot so that the brain does not get the blood it needs. Stroke affects physical limitations and disabilities in carrying out daily living activities. One of the rehabilitation interventions to increase daily living activities among them is propioceptive neuromuscular facilitation. Thisstudy aimed to describe the activity daily living in non-hemorrhagic poststroke patients after propioceptive neuromuscular facilitation intervention. The selection of articles in the study usesthe PICO mnemonic. Searcharticles through the Indonesian Scientific Respirator Research, PubMed, GARUDA, and Google scholar with predetermined inclusion and exlusion criteria. The results show that propioceptive neuromuscular facilitation was proven in increase activity daily living in non-hemorrhagic post-stroke patients. The activity daily living was assessed using Barthel Index checklist. The average of Barthel Index before and after intervention were 42,493 and 75,372 respectively. The propioceptive neuromuscular facilitation has been shown to improve activity daily living in non-hemorrhagic post-stroke patients. Propioceptive neuromuscular facilitation can be a modality treatment to increase activity daily living in non-hemorrhagic post-stroke patients.
\end{abstract}

Keywords: Activity Daily Living, Non-Hemorrhagic Post-Stroke, Propioceptive Neuromuscular Facilitation

\begin{abstract}
Abstrak
Stroke terjadi ketika pembuluh darah yang mengangkut oksigen dan nutrisi menuju otak pecah atau terblokir oleh bekuan sehingga otak tidak mendapat darah yang dibutuhkan. Kejadian stroke memunculkan gangguan keterbatasan fisik dan kecacatan dalam melakukan activity daily living. Peran fisioterapi pada penderita stroke yaitu tindakan rehabilitasi yang dapat meningkatkan ADL salah satuya adalah propioceptive neuromuscular facilitation. Penelitian ini bertujuan untuk mengetahui gambaran activity daily living pada pasien pasca stroke non hemoragic dengan pemberian propioceptive neuromuscular facilitation. Pemilihan artikel pada penelitian ini menggunakan mnemonic PICO. Penelusuran artikel melalui Neliti Respiratori Ilmiah Indonesia, PubMed, Garuda-Garba rujukan digital dan Google scholar dengan kriteria inklusi dan ekslusi yang telah ditentukan. Hasil literature review kelima artikel menunjukkan bahwa PNF terbukti meningkatkan ADL pada pasien pasca stroke non hemoragic dengan hasil rata-rata peningkatan sebesar 32.879 dengan menggunakan alat ukur indeks barthel sebelum intervensi 42.493 dan sesudah intervensi 75.372. Hasil literature review kelima artikel ini menunjukkan bahwa propioceptive neuromuscular facilitation terbukti dapat meningkatkan activity daily living pada pasien pasca stroke non hemoragic. Penetitian ini dapat digunakan sebagai dasar pengembangan praktisi fisioterapi pada masalah peningkatan activity daily living pada pasien pasca stroke non hemoragic dengan menggunakan latihan propioceptive neuromuscular facilitation.
\end{abstract}

Kata Kunci: Activity Daily Living, Propioceptive Neuromuscular Facilitation, Pasca Stroke 


\section{Prosiding Seminar Nasional Kesehatan $\mid 2021$ Lembaga Penelitian dan Pengabdian Masyarakat Universitas Muhammadiyah Pekajangan Pekalongan}

\section{Pendahuluan}

Stroke Cerebro Vascular Accident (CVA) atau gangguan peredaran darah otak merupakan penyakit neurologis yang sering dijumpai dan harus ditangani secara cepat. Gangguan fungsi saraf tersebut dapat menimbulkan beberapa gejala seperti kelumpuhan wajah pada anggota tubuh, bicara tidak lancar, bicara tidak jelas (pelo), perubahan tingkat kesadaran, gangguan penglihatan dan lain-lain [16]. Pasien pasca stroke membutuhkan rehabilitasi untuk mengurangi kecacatan fisik agar dapat menjalani aktivitasnya dengan baik. Pasien dengan gangguan stroke akan mengalami gangguan-gangguan yang bersifat fungsional. Gangguan sensoris dan motorik pasca stroke mengakibatkan gangguan keseimbangan termasuk kelemahan otot, penurunan fleksibilitas jaringan lunak serta gangguan kontrol motorik dan sensorik. Fungsi yang hilang akibat gangguan kontrol motorik pada pasien stroke dapat mengakibatkan hilangnya koordinasi, hilangnya kemampuan keseimbangan tubuh dan postur [1].

Data Riset Kesehatan Dasar (Riskesdas) Nasional tahun 2019, prevalensi stroke di Indonesia mencapai $14 \%$. Diantaranya semua jenis penyakit yang tinggi prevalensinya yaitu stroke, prevalensi stroke dari tahun ke tahun semakin meningkat. Tahun 2018 prevalensi stroke pada angka 9,3\%. Jumlah ini meningkat pada tahun 2016 menjadi 14\%. Provinsi dengan prevalensi stroke tertinggi yaitu di Yogyakarta (16,9\%), Sulawesi Tengah $(16,6 \%)$ dan disusul oleh Jawa Timur dengan prevalensi $(16,0 \%)$ (Kemenkes RI, 2019). Data yang diperoleh dari Dinas Kesehatan (Dinkes) Kabupaten Pekalongan pada tahun 2019 terdapat 866 kasus stroke [5].

Dampak penyakit stroke tersebut menyebabkan pasien mengalami self care deficit atau ketergantungan kepada orang lain dan membutuhkan bantuan keperawatan secara berkesinambungan agar secara bertahap pasien dan keluarga dapat melakukan aktivitas sehari-hari secara mandiri [10]. Activity Daily Living (ADL) merupakan sesuatu yang penting untuk mempertahankan keberlangsungan hidup [19]. Umumnya penderita stroke akan menjadi bergantung pada bantuan orang lain dalam menjalankan aktivitas kehidupannnya sehari-hari (activity daily living) seperti makan, minum, mandi, berpakaian dan transfer. Kemandirian dan mobilitas seseorang yang menderita stroke menjadi berkurang atau bahkan hilang. Berkurangnya tingkat kemandirian dan mobilitas seseorang dapat berpengaruh terhadap kualitas hidup (quality of life) yang dimiliki [7].

Latihan Propioceptive Neuromuscular Facilitation (PNF) merupakan latihan yang memberikan rangsangan pada propioceptor sebagai cara untuk meningkatkan kebutuhan mekanisme neuromuscular yang dibuat lebih bervariasi [23]. Latihan propioceptive neuromuscular facilitation ini mempunyai jenis latihan diantaranya jenis latihan rhytmical initiation, repeated contraction, combination of isotonic, taiming for emphasis, taiming, hold-relax, contrax-relax, slow reversal, stabilizator rhythmic stabillization dan stabilizing reversal yang diyakini sangat efektif dan bermanfaat untuk meningkatkan activity daily living yang mengalami keterbatasan gerak fungsional. Latihan PNF ini bertujuan untuk memperoleh tujuan yang maksimal dari aktivitas yang dicapai dari seseorang dalam setiap melakukan kegiatan [15].

PNF dapat memberikan kemudahan terhadap gerakan dari implus-implus propioseptif. Prinsip umum dari PNF yaitu dengan memberikan stimulasi tertentu 


\section{Prosiding Seminar Nasional Kesehatan $\mathbf{2 0 2 1}$ Lembaga Penelitian dan Pengabdian Masyarakat Universitas Muhammadiyah Pekajangan Pekalongan}

dengan tujuan untuk membangkitkan kembali cara kerja jaringan tubuh yang latent dan sebagai cadangan-cadangannya. Dosis untuk latihan PNF dilakukan 1-3x/minggu selama 12 minggu dengan durasi latihan 30 menit setaip sesinya, maka akan menghasilkan suatu tujuan untuk mencapai suatu gerakan fungsional yang terkoordinasi dan normal [11].

Penelitian yang dilakukan oleh SFS et.al [12] menyatakan bahwa latihan propioceptive neuromuscular facilitation berpengaruh terhadap peningkatan activity daily living pada pasien pasca stroke non hemoragic. Peneliti tertarik untuk melakukan penelitian dengan judul "Gambaran Activity Daily Living pada Pasien Pasca Stroke Non Hemoragic Setelah Pemberian Propioceptive Neuromuscular Facilitation: Literature Review'.

\section{Metode}

Pemilihan Artikel

Pemilihan artikel pada penelitian ini menggunakan PICO, dengan penjelasan sebagai berikut:

a. P (Population)

Pasien pasca stroke non hemoragic yang mengalami gangguan activity daily living

b. I (Intervention)

Penelitian ini menggunakan intervensi propioceptive neuromuscular facilitation

c. C (Comparative Intervention)

Dalam penelitian ini tidak ada pembanding

d. O (Outcome)

Peningkatan activity daily living dengan indeks barthel

\section{Seleksi Studi}

Kriteria inklusi meliputi sesuai dengan kata kunci, artikel yang dipublikasikan dalam rentang tahun 2011-2021, menggunakan Bahasa Indonesia maupun Bahasa Inggris, alat ukur menggunakan Indeks Barthe/ untuk untuk mengukur kemandirian fungsional dalam hal perawatan diri dan mobilitas diri pada keterbatasan aktivitas sehari-hari. Kriteria ekslusi meliputi artikel literature review/systematic review.

\section{Hasil dan Pembahasan}

\section{Hasil}

Hasil penelusuran literature lima artikel dengan pemilihan sesuai kriteria inklusi dan ekslusi. Artikel yang direview menghasilkan data berupa karakteristik demografi, pre test dan post test serta gambaran activity daily living pada pasien pasca stroke non hemoragic setelah pemberian propioceptive neuromuscular facilitation. 


\section{Prosiding Seminar Nasional Kesehatan \\ Lembaga Penelitian dan Pengabdian Masyarakat Universitas Muhammadiyah Pekajangan Pekalongan}

a. Gambaran Karakteristik Responden Berdasarkan Jenis Kelamin

Hasil analisa karakteristik artikel tentang karakteristik jenis kelamin yaitu artikel Prosper, Chuba, Ibeneme, Ihegihu, Afam, Nmankwo dan Onuwa (2017), The, Rusly dan Darwis (2019), Kim, Kyu Lee dan Mi Kim (2015), Kim dan Kang (2019), Bang, Song dan Cho (2018) yang disajikan dalam tabel 3.1:

Tabel 4.1 Gambaran Karakteristik Jenis Kelamin Responden $(n=90)$

\begin{tabular}{ccc}
\hline Karakteristik & \multicolumn{2}{c}{ Responden } \\
\cline { 2 - 3 } & Jumlah & \% \\
\hline Laki-Laki & 46 & $51,1 \%$ \\
\hline Perempuan & 44 & $48,9 \%$ \\
\hline Total & 90 & $100 \%$ \\
\hline
\end{tabular}

Data analisis berdasarkan tabel 4.1 jumlah responden dari kelima artikel yaitu 90 responden. Hasil analisa karakteristik jenis kelamin didapatkan sejumlah 46 responden laki-laki $(51,1 \%)$ dan 44 responden perempuan (48,9\%). Penelitian ini menunjukan bahwa responden laki-laki lebih banyak berisiko mengalami stroke daripada perempuan.

b. Gambaran Karakteristik Responden Berdasarkan Usia

Karakteristik usia terdapat pada artikel Prosper, Chuba, Ibeneme, Ihegihu, Afam, Nmankwo dan Onuwa (2017), The, Rusly dan Darwis (2019), Kim, Kyu Lee dan Mi Kim (2015), Kim dan Kang (2019), Bang, Song dan Cho (2018) yang disajikan dalam tabel 3.2 :

Tabel 3.2 Gambaran Karakteristik Usia Responden (mean)

\begin{tabular}{cccc}
\hline No Artikel & $\mathbf{N}$ & \multicolumn{2}{c}{ Umur } \\
\cline { 2 - 4 } & & Mean & $\begin{array}{c}\text { Total Mean } \\
\text { Usia }\end{array}$ \\
\hline 1 & 50 & 53.94 & 2.697 \\
\hline 2 & 10 & 69,1 & 691 \\
\hline 3 & 7 & 56 & 392 \\
\hline 4 & 3 & 60.42 & 181.26 \\
\hline 5 & 20 & & $31-70$ Tahun \\
\hline Total & 90 & & 56.589
\end{tabular}

Hasil dari karakteristik berdasarkan rata-rata usia pada keempat artikel terdapat 70 responden dengan data analisis didapatkan nilai rata-rata usia 56.589 tahun. Hasil data analisis satu artikel yang terdapat 20 responden tidak mencantumkan rata-rata usia dan didapatkan nilai rentan usia 31-70 tahun.

\section{c. Peningkatan Activity Daily Living}

Variabel peningkatan kemampuan activity daily living didapatkan dalam lima artikel dengan jumlah 90 responden yaitu artikel Prosper, Chuba, Ibeneme, Ihegihu, Afam, Nmankwo dan Onuwa (2017), The, Rusly dan Darwis (2019), Kim, Kyu Lee dan Mi Kim (2015), Kim dan Kang (2019), Bang, Song dan Cho (2018). Nilai rata-rata peningkatan activity daily living disajikan dalam tabel 3.3: 


\section{Prosiding Seminar Nasional Kesehatan $\mid 2021$ Lembaga Penelitian dan Pengabdian Masyarakat Universitas Muhammadiyah Pekajangan Pekalongan}

Tabel 3.3 Gambaran Activity Daily Living pada Pasien Pasca Stroke Non Hemoragic Setelah Pemberian Propioceptive Neuromuscular Facilitation

\begin{tabular}{cc}
\hline Activity Daily Living & Rata - Rata \\
\hline Sebelum diberikan Intervensi PNF & 42.493 \\
\hline Sesudah diberikan Intervensi PNF & 75.372 \\
\hline Peningkatan & 32.879 \\
\hline
\end{tabular}

Hasil data analisis gambaran activity daily living pada pasien pasca stroke non hemoragic setelah pemberian propioceptive neuromuscular facilitation dari lima artikel didapatkan peningkatan activity daily living sebesar 32.879 dengan hasil sebelum diberikan intervensi PNF sebesar 42.493 dan sesudah diberikan intervensi PNF sebesar 75.372.

\section{Pembahasan}

1. Karakteristik Responden Berdasarkan Jenis Kelamin

Hasil dari lima artikel penelitian, responden yang didapatkan berjumlah 90 responden. Karakteristik jenis kelamin didapatkan $51,1, \%$ (46 orang) responden berjenis kelamin laki-laki dan 48,9\% (44 orang) responden berjenis kelamin perempuan. Laki-laki lebih berisiko mengalami stroke, perempuan lebih cenderung mengalami stroke hemoragic [14]. Wanita terdapat hormon estrogen yang dapat menjaga pembuluh darah di otak tetap sehat dengan meningkatkan efesiensi mitokondria dalam pembuluh darah di otak yang mengakibatkan risiko terjadinya stroke lebih banyak terjadi pada laki-laki [4]. Penyebab lain stroke karena pola hidup dan gaya hidup yang banyak ditemukan pada laki-laki yang memiliki kebiasaan merokok yang menyebabkan penyumbatan di pembuluh darah [20]. Hal ini sesuai dengan penelitian Prosper et.al [22] yang menyatakan bahwa laki-laki beresiko terkena stroke dibandingkan perempuan.

2. Karakteristik Responden Berdasarkan Usia

Karakteristik responden menurut usia dengan jumlah responden 90 responden. Karakteristik usia didapatkan hasil usia responden rata-rata 56,589 tahun. Stroke biasa menyerang pada usia diatas 40 tahun, namun dengan jenis makanan yang ada saat ini menutup kemungkinan stroke dapat menyerang seseorang pada usia muda [18]. Hal ini sesuai dengan penelitian Ezema et al [9] stroke dapat terjadi pada segala jenis usia dan kejadian stroke meningkat setiap pertambahan sejak usia 40 tahun keatas. Faktor yang berpengaruh terhadap terjadinya stroke pada usia muda dibawah 40 tahun dengan riwayat hipertensi, kolestrol dan riwaayat stroke pada keluarga.

Hasil karakteristik jenis stroke didapatkan hasil stroke iskemik lebih banyak ditemukan dibandingkan stroke hemoragic. Empat faktor resiko tertinggi yang berkontribusi terhadap munculnya stroke iskemik diantaranya adalah usia lebih dari 50 tahun $(45,83 \%)$ dan kolesterol meningkat $(43,76 \%)$ yang mempengaruhi penyempitan pada pembuluh darah, gula darah yang semakin meningkat dan hipertensi $(43,76 \%)$ yang mempengaruhi tekanan perfusi di otak [13]. Faktor 


\section{Prosiding Seminar Nasional Kesehatan $\mid 2021$ \\ Lembaga Penelitian dan Pengabdian Masyarakat Universitas Muhammadiyah Pekajangan Pekalongan}

risiko ini berkontribusi terhadap penuruanan suplai oksigen melalui aliran darah ke otak yang dapat menyebabkan stroke iskemic.

\section{Hasil Peningkatan Activity Daily Living}

Hasil literature review pada 5 artikel didapatkan rata-rata dosis latihan propioceptive neuromuscular facilitation $1-3 x$ /minggu selama 12 minggu dengan durasi waktu 30 menit setiap sesinya. Hasil peningkatan kemampuan activity daily living pada pasien pasca stroke non hemoragic dengan alat ukur indeks barthel dengan penyajian nilai yang sama pada ke 5 artikel yaitu pada penelitian Prosper, Chuba, Ibeneme, Ihegihu, Afam, Nmankwo, Onuwa (2017), The, Rusly, Darwis (2019), Kim, Kyu Lee, Mi Kim (2015), Kim dan Kang (2019), Bang, Song dan Cho (2018). Hasil peningkatan dari kelima artikel didapatkan nilai sebesar 32.879 dengan rata- rata nilai pre test sebesar 42.493 dan rata-rata nilai post test sebesar 75.372. Hasil tersebut menunjukkan bahwa propioceptive neuromuscular facilitation mampu meningkatkan kemampuan activity daily living pasien pasca stroke non hemoragic.

Sekitar $80 \%$ populasi pasien stroke mengalami keterbatasan activity daily living sebesar $50-80 \%$ pasien bahkan 2-6 bulan [21]. Pasca stroke terjadi setelah 3 bulan pasca serangan, Fase ini dibutuhkan terapi untuk memulihkan gerak dan fungsi pasien [3]. Stroke subakut berlangsung mulai dari 2 minggu samapi 6 bulan pasca stroke serta merupakan fase yang penting untuk dilakukan pemulihan fungsional (golden period). Fase ini kondisi media dan hemodinamik telah stabil serta adanya proses pemulihan, reorganisasi pada sistem saraf sehingga dapat mengoptimalkan pemulihan setelah stroke [2]. Rehabilitasi pada pasca stroke paling tepat dilakukan 24-48 jam setelah serangan stroke dengan catatan bahwa kondisi pasien telah stabil [17].

Latihan propioceptive neuromuscular facilitation (PNF) berfokus pada penyusunan latihan-latihan dalam patron-patron gerakan yang selalu melibatkan lebih dari satu sendi dan mempunyai tiga komponen gerakan [6]. PNF adalah salah satu stretegi rehabilitasi yang digunakan terutama pada pasien pasca stroke. PNF dikembangkan berdasarkan teori pembelajaran fasilitas pada sistem neuromuskuler dengan merangsang propioseptif [9]. Indeks barthel digunakan untuk menilai kembalinya fungsi kemampuan ataupun gangguan neurologi lainnya dengan skor penilaian 1-10 indikator dengan nilai maksimal 15 skor dengan interpretasi hasil nilai 0-20 (Ketergantungan penuh), 21-61 (Ketergantungan berat), 62-90 (Ketergantungan moderat), 91-99 (Ketergantungan ringan), 100 (Mandiri).

Hasil penelitian yang dilakukan oleh SFS, Astrid dan Adyatmaka (2019), Prosper, Chuba, Ibeneme, Ihegihu, Afam, Nmankwo dan Onuwa (2017) menyatakan bahwa latihan propioceptive neuromuscular facilitation mampu meningkatkan activity daily living pada pasien pasca strokenon hemoragic. Penelitian ini sejalan dengan penelitian Ezema, Nweke, Uroko, Uduonu dan Uchenwoke (2018), The, Rusly dan Darwis (2019), Kim, Kyu Lee dan Mi Kim (2015) bahwa latihan propioceptive neuromuscular facilitation mampu meningkatkan activity daily living pada pasien pasca stroke non hemoragic. 


\section{Prosiding Seminar Nasional Kesehatan $\mathbf{2 0 2 1}$ Lembaga Penelitian dan Pengabdian Masyarakat Universitas Muhammadiyah Pekajangan Pekalongan}

\section{Kesimpulan}

Data analisis berdasarkan tabel 4.1 jumlah responden dari kelima artikel yaitu 90 responden. Hasil analisa karakteristik jenis kelamin didapatkan sejumlah 46 responden laki-laki $(51,1 \%)$ dan 44 responden perempuan $(48,9 \%)$. Penelitian ini menunjukan bahwa responden laki-laki lebih banyak beresiko mengalami stroke daripada perempuan. Hasil dari karakteristik berdasarkan rata-rata usia pada keempat artikel terdapat 70 responden dengan data analisis didapatkan nilai rata-rata usia 56.589 tahun. Hasil data analisis satu artikel yang terdapat 20 responden tidak mencantumkan rata-rata usia dan didapatkan nilai rentan usia 31-70 tahun. Hasil data analisis gambaran activity daily living pada pasien pasca stroke non hemoragic dengan pemberian propioceptive neuromuscular facilitation dari lima artikel didapatkan peningkatakan activity daily living sebesar 32.879 dengan hasil sebelum diberikan intervensi PNF sebesar 42.493 dan sesudah diberikan intervensi PNF sebesar 75.372.

\section{Saran}

Hasil dari penelitian ini dapat digunakan sebagai dasar pengembangan praktisi fisioterapi pada masalah peningkatan activity daily living pada pasien pasca stroke non hemoragic dengan menggunakan latihan propioceptive neuromuscular facilitation.

\section{Referensi}

[1] A. Ali, "IImu Kedokteran Lengkap tentang Stroke", D-Medika: Yogyakarta, 2013

[2] A. C. Sardjito, "Pelatihan Miror Neuron System Sama dengan Pelatihan Propiceptive Neuromuscular Facilitation dalam Meningkatkan Fungsional Anggota Gerak Atas Pasien Pacsa Stroke" in Jurnal Fisioterapi, vol. 13, no. , 2019.

[3] Beackers, "Latihan Propioceptive Neuromuscular Fasilitation terhadap Peningkatan Activity Daily Living Pasien Pasca Stroke" in Idea Nursing Journal, Prodi Keperawatan Poltekkes Kemenkes Bengkulu, 2014

[4] Dandayani, "Konsep dan Penatalaksanaan dalam Praktik Keperawatan Stroke", Jakarta. Salemba Medika, 2017

[5] Dinas Kesehatan Kabupaten Pekalongan, "Laporan Penyakit Tidak Menular. Data Dinas Kesehatan Kabupaten Pekalongan", 2019

[6] Flett, "Comparison of Brunnstrom Movement Therapy and PNF in Rehabilitation of Post Stroke: A Randomized Trial" in Journal of Bodywork \& Therapy, India, 201

[7] Hariandja, "Pengaruh Pemberian Latihan Propioceptive Neuromuscular Fasilitation terhadap Peningkatan Activity Daily Living pada Pasien Pasca Stroke di RSUD Gambiran", Fakultas Ilmu Kesehatan-Universitas Kediri, 2013

[8] I. Ezema, C. Nweke, U. Uroko, M. Uduonu, M and U. Uchenwoke, "Bobath versus Propioceptive Neuromuscular Facilitation in Retraining of Balance and Functional Independence in Activities of Daily Living" in Asian Journal of Research and Reports in Neurology, vol. 1, no. 1, pp. 1-15, 2018. 


\section{Prosiding Seminar Nasional Kesehatan Lembaga Penelitian dan Pengabdian Masyarakat Universitas Muhammadiyah Pekajangan Pekalongan}

[9] I. Ezema, C. Nweke, U. Uroko, M. Uduonu, M and U. Uchenwoke, "Bobath versus Propioceptive Neuromuscular Facilitation in Retraining of Balance and Functional Independence in Activities of Daily Living" in Asian Journal of Research and Reports in Neurology, vol. 1, no. 1, pp. 1-15, 2018.

[10] L. Suhardinigsih, I. Bakara, M. Davis and A. Maratis, A, "Faktor yang Mempengaruhi Kejadian Stroke di Rumah Sakit Umum Daerah Provinsi Riau", in Quality Jurmal Kesehatan, Jurusan Keperawatan Poltekkes Kemenkes Tanjungpinang Jakarta, 2013

[11] M. Irfan, "Buku Ajar Pemeriksaan dan Pengukuran Fisioterapi". Yogyakarta: CV. Budi, 2014

[12] M. SFS, S. Sihombing, Y. Alfi, N. Naisa, K. Adam, and K. Hamra, "Hubungan Umur, Jenis Kelamin, dan Hipertensi dengan Kejadian Stroke. Program Pendidikan Dokter, Bagian Neurologi dan Bagian Ilmu Penyakit Dalam", Fakultas Kedokteran-Universitas Halu Oleo, 2015

[13] N. Handayani, A. Vero, A. Fattah, H. Rian and L. Dominica, "Gambaran Drug Related Problem's (DRP's) pada Penatalaksaaan Pasien Stroke Haemoragik dan Stroke Non Haemoragik di RSUD Dr M Yunus Bengkulu" in Jurnal Farmasi dan IImu Kefarmasian Indonesia, Program Studi Farmasi Fakultas MIPA-Universitas Bengkulu, vol. 5, no. 1, 2019

[14] R. A. Nably, R.A, "Deteksi Dini \& Pengobatan Stroke". Aulia Publishing: Yogyakarta, 2012. pp. 48

[15] R. Satia, S. Ayas, N. Wijaya and B. Ignat, "Effect of Propioceptive Neuromuscular Fasilitation on Upper and Lower Extremity in Activity Daily Living in Stroke Patient: a Randomized Controlled Trial" in Journal of Physical Therapy Science, 2017. pp. $16-17$

[16] Riset Kesehatan Dasar, "Badan Penelitian dan Pengembangan Kesehatan Kementrian Kesehatan RI", 2013.

[17] S. L. Adrian and P. Pandeiroth, "Miror Therapy in Stroke Rehabilitation" in Jurnal Biomedik, vol. 6, no. 2, pp. 84-9, 2018

[18] S. La Ode, S, "Asuhan Keperawatan Gerontik", Nuha Medika: Yogyakarta, 2017

[19] Sugiarto, "Penilaian Keseimbangan dengan Aktivitas Kehidupan Sehari-Hari pada Pasien Sroke Dengan Menggunakan Indeks Barthel", Jurusan Pendidikan Kesehatan dan Rekreasi FIK Universitas Negeri Yogyakarta, 2015.

[20] Syaifuddin, "Buku Anatomi Fisiologi Kurikulum Berbasis Kompetensi untuk Keperawatan dan Kebidanan", Edisi-4, 2015.

[21] U. Prosper, G. Chuba, G. Ibeneme, I. Ihegihu, V. Afam, N. Nwankwo and J. Onuwa, "Effects of Propioceptive Neuromuscular Facilittaion and Balance Training on Activities of Daily Living (ADL) Stroke Survivors with and without Cognitive Impairment" in International Journal of Stroke Research, vol. 5, hal.1 pp. 1-9, 2017. 


\section{Prosiding Seminar Nasional Kesehatan 2021 Lembaga Penelitian dan Pengabdian Masyarakat Universitas Muhammadiyah Pekajangan Pekalongan}

[22] U. Prosper, G. Chuba, G. Ibeneme, I. Ihegihu, V. Afam, N. Nwankwo and J. Onuwa, "Effects of Propioceptive Neuromuscular Facilittaion and Balance Training on Activities of Daily Living (ADL) Stroke Survivors with and without Cognitive Impairment" in International Journal of Stroke Research, vol. 5, hal.1 pp. 1-9, 2017.

[23] W. Arif, "Pengaruh Penerapan Propioceptive Neuromuscular Fasilitation (PNF) terhadap Peningkatan Activity Daily Living pada Pasien Stroke" in Jurnal Penelitian Kesehatan, Universitas Esa Unggul in Jakarta, vol. 12, no. 3, 2019. 